\title{
A RESEARCH ON STRESS TESTING APPROACH TOWARDS EVALUATING CREDIT RISK OF A FINANCIAL INSTITUTION
}

\author{
S M Nazmuz Sakib \\ Graduate of BSc in Business Studies \\ School of Business And Trade \\ Pilatusstrasse 6003, 6003 Luzern, Switzerland \\ sakibpedia@gmail.com \\ Student of Department of Law \\ Dhaka International University \\ House \# 4, Road \# 1, Block - F, Dhaka 1213 \\ sakibpedia@students.diu.ac
}

\section{Abstract}

The stress testing methodology should be implemented and applied to the entity's overall financial system at least annually, and if the organization operates in a volatile economy, it should be performed at least twice a year. Finally, managers should include regular training and development sessions for relevant employees of their organization to be fully informed and more informed and informed, considering the evolving science, theory and practicality of a discrete range of stress testing mechanisms that can be appropriately applied to overall financial framework and system of multiple financial institutions and banks. In addition, stress testing is essentially a methodology that collects and analyzes certain future macro-prudential and microprudential economic drivers and indicators, the primary purpose of which is to assess the future 
financial and economic well-being, level of growth and status quo of a financial institution, bank, organization, credit institution or economy or the nation as a whole. In addition, several of these reviews were specifically focused and incorporated into the paper, which substantially and broadly discussed and summarized the importance, feasibility and implementation and conclusions of different stress testing approaches for financial institutions and banks, especially in European and Chinese countries. region. with the primary intention of assessing the future

financial and economic well-being, level of growth and status quo of a group of financial institutions, banks, organizations, credit institutions or the economy or the nation as a whole. In addition, several of these reviews were specifically targeted and incorporated into a paper that substantially and broadly discussed and summarized the importance of the feasibility and implementation and conclusions of different stress testing approaches for financial institutions and banks, especially in European and Chinese countries. region. with the primary intention of assessing the future financial and economic well-being, level of growth and status quo of a group of financial institutions, banks, organizations, credit institutions or the economy or the nation as a whole. In addition, several of these reviews were specifically focused and incorporated into the paper, which substantially and broadly discussed and summarized the importance, feasibility and implementation and conclusions of different stress testing approaches for financial institutions and banks, especially in European and Chinese countries. region. the level of growth and status quo of the financial institutions, banks, organizations, credit institutions or the economy or the nation as a whole. In addition, several of these reviews were specifically focused and incorporated into the paper, which substantially and broadly discussed and summarized the importance, feasibility and implementation and conclusions of different stress testing approaches for financial institutions and banks, especially in European and Chinese countries. region. the 
level of growth and status quo of the financial institutions, banks, organizations, credit institutions or the economy or the nation as a whole. In addition, several of these reviews were specifically focused and incorporated into the paper, which substantially and broadly discussed and summarized the importance, feasibility and implementation and conclusions of different stress testing approaches for financial institutions and banks, especially in European and Chinese countries.

Keywords: Stress Testing, Credit Risk, Credit Risk Testing, Evaluation of Credit Risk, Credit Risk Management, Organizational Management

\section{CHAPTER 1: INTRODUCTION}

\section{1: Background of the research topic}

Last few decades have proved to be very effective, efficient, immense, technical, developing, and innovative and approached based for the entire framework of many business carried out by thousands of organizations around the world and their various core functions or departments, in particular. Among wide range of functional aspects of business and its different classes, one of the attractive and truly emerged form of business concerns in recent times, is the development of financial institutions and specialized banking sectors all over the globe. However, it is also quite relevant and realistic that the entire channel of global financial markets has gone through an immense and a series of dramatic and watchful changes resulting in the financial systems and financial markets transforming into more complexes and assorted structure. 
Also, such increasing complexity has truly raised the concerns and questions for many forms of related business entities specialized in financing and banking needs. Thus, they felt for the need to introduce a wide range of risk management techniques and credit risk analysis tools, with the help of regulators, which should be implemented by these financial institutions in order to mitigate their number of different and distinct and possible risk factors. Furthermore, the growing number of risk management techniques and evolution of the financial systems is due to the economic crisis that is experienced over time and time again (Hall, 2006).

Hence, one of such unique technique related to risk management field is known as "Stress Testing Approach". This approach or technique is basically adopted and employed by most of the financial institutions in order to mitigate the emergence of credit risk on their organization to considerable extent. In addition, this phenomenon is also used to evaluate the impact of various changing economic events or their vulnerabilities, on the overall current and future performances and profit abilities of various financial markets and financial institutions. However, it is significantly noted by different school's scholars and experts that stress testing approach is mainly used as a complimentary tool along with other risk management tools such as Value at Risk and etc. (Kida, 2008).

A stress testing can be regarded as one of the key risk management approach which comprehensively, allows a financial or credit risk manager to effectively carry out, a forwardlooking analysis and evaluation, towards the identification of possible and potential risks that may negatively or adversely affect the well-being of not only financial business but as well as to ultimate system of finance, as a result of substantial potential shocks or economic crisis in future time frame (Oung and Bandt, 2004). Further, financial institutions effectively carry out techniques of stress testing so that they can properly evaluate the impact of different economic 
events, especially macro ones, on their related sectors, examine the sensitivity of extreme events on the credit factors, determine the hidden correlations between the stocks within the portfolio, decide on the possible capital requirements that business will need in future and finally, evaluate the decisions pertaining to portfolio allocations beyond normal market conditions and under potential future credit environments (Sorge, 2004).

After the East-Asian crisis, stress testing technique significantly gained immense importance and prominence, as a risk management technique and also, after the Global Finance Crisis, the technique became widely accepted for identifying potential fluctuations, shortcomings and vulnerabilities on the face of financial system (Goddard and Melville, 2004). Further, in 1990s, in response to the impact of the various economic events on the financial markets, IMF also introduced "Financial Sector Assessment Program (FSAP)" in collaboration with the World Bank. Even though, today, also a great number of smart, potential and stable financial institutions widely use and apply the stress testing technique in order to evaluate the intrinsic strength of the internal system, environment and control.

In addition, IMF Working Paper that increase in disposable income, low interest rates and substantial growth in employment, all contributed in driving up the housing prices and therefore, resulted in growing the mortgage lending (Slack, Hilbers and Jones, 2004). Furthermore, the financial statements of many banks, including their income statement and balance sheet, also reflect stronger dependence on mortgage lending, in terms of both increase in income and stock of assets. The authors further mentioned that, by looking at these market conditions at the time of the financial crisis when unemployment was on the rise and disposable income was significantly declining, many financial institutions decided to carry out stress testing approach so as to 
examine the impact of these factors on the performance and profitability of their respective institutions.

Hence, the point to understand is that, if such an approach is properly and timely carried out and the outcomes are effectively implemented across the whole organization related systems and department, then the effects of increment of losses from the current economic crisis can be reduced to great extent and consequently, financial institutions would increase their capital adequacy requirements in a reasonable timeframe.

Thus, this research paper mainly looks at how the practice of stress testing has evolved over time along with any impact of the stress testing on the financial institutions. In addition, the dissertation will evaluate that how financial institutions can address to their sovereign risks and counterparty risks along with measures that can be adopted to reduce risk related to credit. The research paper will also provide recommendations on how the credit risk can be mitigated, using stress testing risk management technique.

\section{2: Aim and Objective of the Research}

The primary aim of this paper is to review the various quantitative methods and techniques developed by global authorities for implementing the stress testing approach towards the credit risk aspects of financial institutions, along with focusing in particular, on the techniques used to connect various macroeconomic drivers related to stress on financial institutions specific needs of credit risk. Furthermore, authorities with a core mandate and responsibility for maintaining the overall financial stability and management, are significantly and particularly more interested in quantifying the numbers from macro to micro connecters and 
linkages and thus, have successfully developed many specific models, which are quite expertise and smart in the field of stress testing methodology.

Furthermore, the main aim of this research paper is to evaluate that how stress testing technique can be used to evaluate the credit risk experienced by financial institutions and in their specific business functions and operations which are related to credit, in particular. Moreover, the research paper would basically be focused at the credit risk, generally, experienced by Chinese and European financial institutions. In addition to this, the extensive analysis of this paper, will also provide justification for other research objectives and aims which also include;

- To assess the sovereign risk and credit risk of Chinese and European financial institutions

- To identify steps and techniques to mitigate credit risk

- To implement stress testing to evaluating the credit risk of the financial institutions

- To recommend measures and techniques for credit risk management

\section{3: Research Questions}

The research paper is focused at answering the main research question which is how stress testing can be used to evaluate the credit risk experienced by financial institutions. In addition to this, the research paper also provides answers to the following research questions which are as follows;

1. What are the sovereign risk and counterparty risk faced by Chinese and European financial institutions?

2. What are the ways to mitigate credit risk?

3. How credit risk can be managed by the financial institutions? 


\section{4: Significance of the Research paper}

The research paper would prove to be quite essential and effective for a great number of population residing at the nook and corner of China and Europe, because it would be highlighting with some of the basic guide, understanding and the ways of implementation of stress testing approach, which is required to analyze various credit risk factors in a financial institutions. Thus, this study and research paper would prove to be as a significant and relevant information and guide for those masses who are basically interested in analyzing this approach in line with the Chinese and European financial institutions.

Moreover, briefly stating, stress testing is mainly used as a risk management tool, where majority of the financial institutions performance is tested via stress testing, in order to evaluate the impact of major economic factors, drivers and events on the ultimate performance and profitability of their financial system. Moreover, the extensive content analysis would also provide, that most of the research papers are carried from the U.S. perspective and financial system, but on the other hand, this report will provide insights into, how stress testing can be used by Chinese and European financial institutions to examine their respective credit risks. As a result, the outcome of the research paper can then be effectively used by the managers of Chinese and European financial institutions, so as to mitigate the several number of credit risks that may resulted in substantial extent of losses, at the time of future or expected economic crisis in near future.

In addition, the importance of this paper would also entail significantly towards generic class of people as well, who do not have any previous knowledge or information with respect to the subject of stress testing approach related to credit risk analysis and assessment. The class of such person would be comprehensively informed and educated, once they consider this paper in 
order to assess and understand the background and practicality of various issues that surrounds to the phenomena of stress testing and its various forms and kinds. Hence, after the thorough glance and study of this paper, they would then be in a good position to properly understand, further explain and implement the wide range of practical issues associated with the subject in their respective practical life's scenario as well. Moreover, the particular study and research related to the economies of Chinese and European financial markets, and how the stress testing approach becomes the needs and requirements of such markets in recent times would be an added knowledge to the users of this report.

As the stress testing principles and methods, primarily suggests and recommends the range of financial institutions and banking channels with key future economic and financial scenarios, on the basis of certain prudential economic drivers, thus, its importance is much to these sectors in order to guide them related to the areas of business liquidity maintenance, cash flow ratios, lending requirements and ratios and etc. Furthermore, its importance would also be understood by the users from the time of recent and past economic crunch down at the global level as well. For instance, few of the key lessons that is being learnt during the time of economic crisis, and given the extreme funding and cash flows pressures sighted or experienced by most of the financial institutions during this period, it Is foremost essential to maintain an adequate level of liquidity with the respective financial institutions, which includes, a sufficient stock of cash and unencumbered quality of liquid assets which can be easily converted into cash form (Federalreserve.gov, 2014). 


\section{CHAPTER 2: LITERATURE REVIEW}

\section{Stress Testing}

The current Global Financial Crisis of 2009-2009 reflected that how changes in the market conditions can cause numerous strains on the financial performance and profitability of the banks. One evidence of this consequence is that stress testing which is defined as one of the risk management techniques that can be used to examine the vulnerabilities of a portfolio with respect to changes in the macroeconomic environment or economic events, as cited by Basel Committee on Banking Supervision (2008). Committee on the Global Financial System (2001) mentioned that stress testing is used by financial institutions to make risks that are experienced by institutions more transparent and therefore, by calculating the potential losses on a portfolio in abnormal markets. In addition to this, the author mentioned that stress tests are often used to complement other risk management techniques for internal control and management systems that are set in place by the financial institutions such as banks and other institutions based on which capital allocation decisions are made.

Edrington and Guan (2006) asserted that in regard to the asset markets, the historical returns of the portfolio does not reflect any information related to the probability of economic events therefore stress testing provide a useful complement to other major risk management techniques to evaluate the behavior of portfolio under abnormal market conditions. In addition to this, financial institutions usually apply stress testing to individual institutions or portfolio of stocks in an attempt to gauge the market risk where the stress testing is mainly done to evaluate the components of portfolio along with other risks that may influence the value of the portfolio. 
Research has provided that stress testing has gained a prominent place in terms of risk management techniques within the context of financial institutions such as large and small banks. Fender, Gibson and Mosser (2001) discussed that the current supervisory guidance set out that banks having substantial concentrations in the area of real estate and subprime lending should carry out the stress testing to evaluate the exposure of their portfolio along with other risk management techniques such as VaR. Furthermore, other standard asset-liability management techniques form the stress testing methods which may include methods to evaluate the effect of interest rate shocks and interest rate simulations which are carried out to assist the organization in meeting the finance requirements under stressed conditions, as explained by Martin (2007).

\section{Stress testing on Chinese banks}

China, a country known by its huge population and progressing day by day for its developing approach in most of the fields, aspects and directions of business platforms, is also have some due reservations and considerations for its financial institutions in recent times as well. As witnessed in the global economic crises in the phase of 2008 and 2009, most of the countries of the world, including China, deeply fall into its meltdown and waves and still some parts of its economy yet to completely recover from the aftereffects of such waves of economic downfall.

And as the China Banking Regulatory Commission (CBRC), has recently said that it will strongly conduct and organize the regional level and national level programs for stress testing for its various range of banking channels and financial institutions (report, 2014). This action was spot on taken by CBS, after it has noticed that wide range of its banking circle had significantly witnessed a spike in their bad loans in the last financial year. Further, the fact was also seconded by the Shanghai Securities News which has clearly reported such facts and figures in recent 
times and which substantially reflects the growing concerns of some creditworthiness aspects for a number of banks in China.

Furthermore, the regulator also quoted in sending its guidelines to various banks in recent times pointing the issue under discussion that all CBRC official branches and their supervisory departments should immediately organized certain valid and appropriate stress tests for its banking institutional and organizations in a secure and timely manner, as this action on their part would substantially help them to evaluate the impact of unfavorable events and situations in terms of individual banks scale and the overall system of banking as well and will probably urge the banking financial institutions to cater for and make up any emergency plans for future financial needs and requirements in particular (Chinadaily.com.cn, 2014).

Hence, the above action on the part of $\mathrm{CBRC}$, would entail the wide number of identified banking networks and financial institutions practicing in China, to carry out certain thorough strategies of stress testing on its various risk management issues pertaining to credit and related areas. In essence, as a result of taking the substantial benefits from stress testing approach, banks should properly and deeply study various risk situations in their key and core business regions, focus their attention to certain industries level risks and issues and on certain significant and vital business clients.

From way back of time and nowadays too, many Chinese banks are still dealing with some of the aftermaths and impacts of the huge lending binge that policymakers unleashed to soften the impact of the global financial crisis in 2008 (report, 2014).

The CBRC's 2014 guidelines also urged, that banks should immediately curb the lending requirements to various local government financial vehicles (LGFVs) in particular and also to certain industries, which are specially facing some overcapacity in its overall macroeconomic 
scale, including property, real estates and steel trading enterprises. Consequently, the accountability of banks towards the regulatory bodies would be reduced to greater extent, and in generic terms, it would also be quite secured in terms of defending its overall level of credits risks exposure in both local and industrial level.

Thus, the approach of stress testing to analyze and critically evaluate and control the credit risks related issues in some of the banking channels in the region of China, is also considered essential and appropriate. Therefore, the importance of stress testing approach could not be under rated and ignored in most of significant or even trivial part of the world.

\section{Solvency Stress testing}

The global financial and economic crisis or meltdown has placed some of the substantial scale of spotlight squarely and particularly on bank stress testing's techniques, which was due to realistic need of time. Stress tests primarily conducted and carried out majorly in the phase of the lead-up to such crisis, particularly, including those carried out by IMF staff, were not considered as always able to spot or identify the correct and genuine level of risks, credit threats and economic vulnerabilities with which a particular banking organization may be or would be affected (A. Jobst, Lian Ong \& Schmieder, 2013). Thereafter, IMF staff and support team has focused their attention in developing rather more robust, result oriented and consistent stress testing methods, techniques and models and hence, keenly adopted a more consistent, integrated and coherent approach.

In particular, a solvency testing approach of stress tests could successfully be articulated and applied in testing the overall stress testing mechanism, for IMF's surveillance of its member countries', which mainly includes their banking systems and financial institutions. Furthermore, the approach of solvency testing mechanism generated by IMF staff in order to get and attain 
more consistent and clear results on the future performance and economic indicators and drivers for various banking institutions of its member countries have also been depicted with the help of the following diagram.

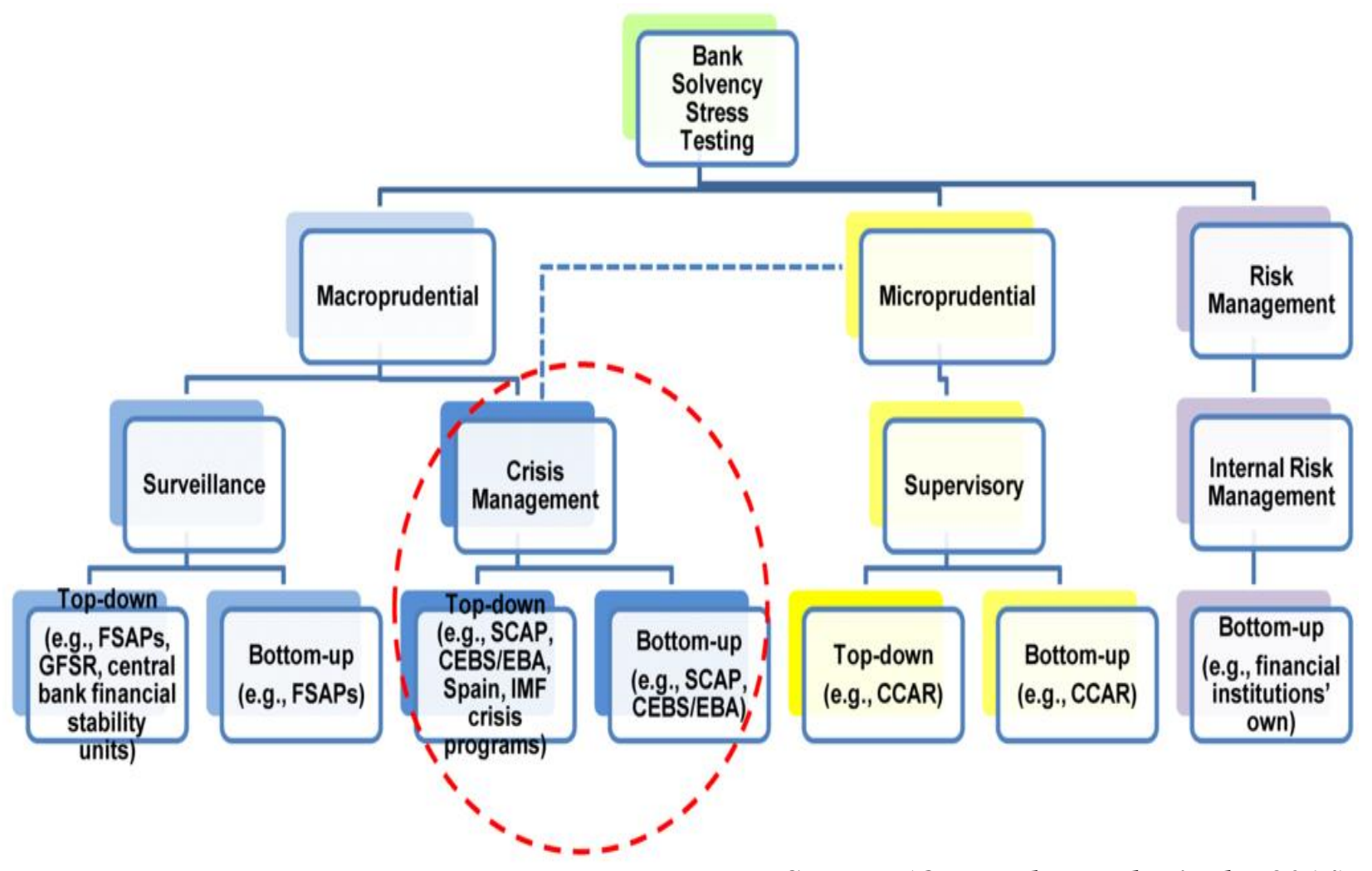

Source: (Ong and Pazarbasioglu, 2014)

Stress testing conducted and developed by IMF with the support of its technical staff and team, is considered primarily as a part of the institution's surveillance mandate and is typically based for macroprudential purposes and aspects (IMF/World Bank, 2003; Moretti and others, 2008). The main aim of the testing mechanism was to assess and analyze the ultimate systemwide resilience and its ability to tolerance and endurance to various shocks and vulnerabilities over the period medium-term and long term, unveiling the possible vulnerabilities to any recent and rapid devastation, deterioration and downfall in the macroeconomic scale and environment. 
And, most specifically playing its vital role and function in the identification of substantial level of potential threats and dangers to the overall economic and financial stability of financial and banking institutions.

Thus in particular giving reference to the context under discussion, IMF stress tests both the risks which was associated to solvency and liquidity in totality, and notably in FSAPs, to tend to implicate and incorporate very intense stress and credit tension scenarios in order to assess the overall capability of the entire financial system so as to withstand the ultimate tail risks.

The findings of the IMF's surveillance stress tests typically do not require management action by financial institutions; rather, they are used to inform policy discussions with country authorities about the frameworks in place to deal with systemic shocks and hazards (Bayoumi and Vitek, 2011). Overall, the robustness, consistency and credibility of IMF tested and developed stress tests were largely affected and dependent on the scale of the coordination and cooperation level extended by other country authorities as well, which was also considered as one of the crucial aspects in terms of the development of this ultimate solvency test model of credit and risk for financial institutions (Howard, 2009).

\section{Macro prudential stress testing mechanism}

Since the 2007 financial crisis, evaluations of the soundness of banks have emerged as a major theme to promote the stability of the global financial system through which financial institutions are assessed against macroeconomic variable indicators of macro-scenarios, such as the long-term treasury yield, GDP growth, exchange rate, and unemployment rate (Nttdata.com, 2014). 
Macro prudential stress tests mainly focus its areas of concerns on the subject that encompasses on whether the banking system in generic terms and as a whole possess the balance sheet capability and capacity in order to support the national economy of the country in which it is operating (Greenlaw et al., 2011). A central aim or goal which is averting rather runs on the realty, on systemic banks and financial institutions, by certain wholesale suppliers and creditors of credits tools and instruments that significantly lead to the overall contraction and compression of credits to these institutions and merely damage the ultimate broader economic aspects of a country.

Thus, to smartly avoid such aggregate deleveraging in the key periods of economic or financial distress or downfall, remedies should rather be focused on developing and raising some new capital ventures and measures which must be in terms of dollars or Euros currency frameworks, in spite on merely satisfying certain range of general capital ratios (Lannoo, 2010). Thus, a valid argument is observable from the point portrayed from the references above, which primarily signifies that the banks should have to be solvent in sufficient terms to avoid any sort of economic downturn on rigorous basis. Further, the run point of established and systemic bank institutions must be entailed significantly on higher capital maintenance and management rather than to expose itself to the ultimate insolvency point of scale.

Moreover, macro-economic factors are widely considered and regarded by most of school of thoughts and modern-day experts, as the substantial drivers and determinants that could effectively depicts the future resistance capabilities for banking and financial institutions during the times of economic and financial crunches. In essence, the approach merely discussed with the help of macro prudential stress testing approach, clearly signifies that the banks should keenly 
and consistently maintained, managed and control its balance sheet figures related to credit providing schemes, specifically to and including, loans schemes, debts of various nature especially pertaining to credit bulk customers and long-term debt servicing covenants. Because, the proper and consistent management and control of these aspects on the face of balance sheet of any banks, would pre-handedly puts the economic and financial position of such bank to a secure level and thus, as a result the possible outcomes with respect to stress test on credit risks for such banks would portray some desirable and positive effects in the long run.

\section{Sensitivity test approach}

Committee on the Global Financial System (2001) mentioned that stress testing can be done through two main methods including Sensitivity tests which are used to examine the impact of changes in the financial variables on the values of the portfolio without providing the exact details of these vulnerabilities. The advantage of this test is that the technique can be implemented quickly and easily where the financial variable is found to have any previous impact on the value of the portfolio. On the other hand, the limitations of the tests are that the lack of previous events in the past might lead to wrong decisions in the future within the financial institutions. The second method is scenario-based analysis which is explained in the following section.

\section{Scenario based approach}

Scenario based tests which is another technique for stress testing which is used to evaluate the value of portfolio is response to certain past events that may have had a substantial influence over the value of the portfolio. Under this strategy, risk managers of company identify 
some of the financial variables that are susceptible to risk experienced by the portfolio and based on these scenarios these managers predict the future occurrence of these variables. Compare to sensitivity analysis, scenario-based analysis is more widely used because it is more accurately reflects the segments of the business that is expose to changes in the financial variables which can be examined without making any assumptions (Fiedler, 2002). The table below provides the steps through which capital allocation can be strengthened through stress testing method;

Figure 1: The capital allocation through the stress testing method
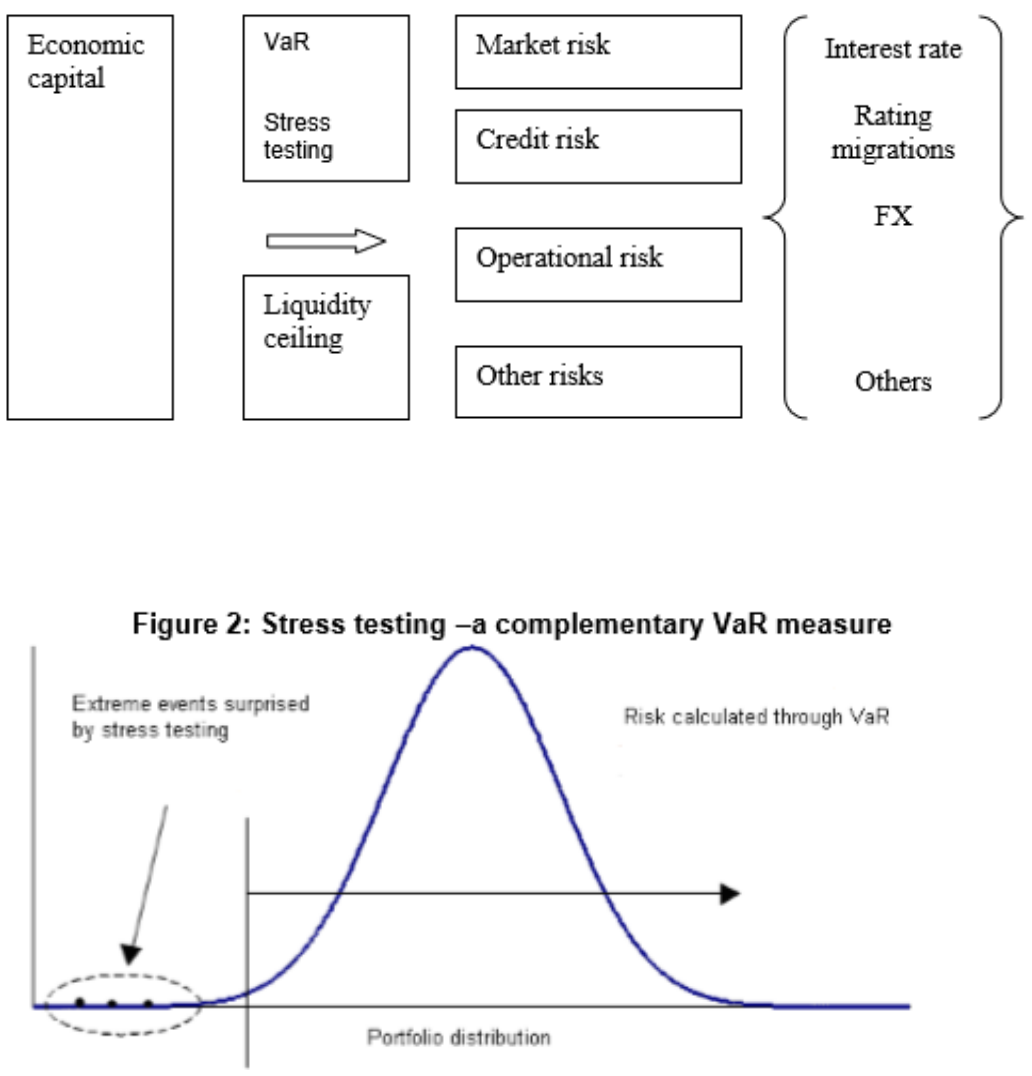

According to the research paper by Alessandriet al (2007) that financial institutions have developed a number of quantitative methods to carry out stress test on the financial sector which is likely to provide information related to the strength of the system under possible economic 
shocks and events which will enable the policy makers to decide on the factors that are significant for causing vulnerabilities in the financial system. The author further mentioned that stress testing with the focus on credit risk of the financial institutions is a critical element of the framework which is drafted to make explicit reference to the economic events. Studies highlighted that changes in the micro variables of banks in response to changes in the macroeconomic variables reflect a great number of challenges for individual banks. Andersen et al (2008) mentioned that due to growing important of financial stability, financial institutions including banks are concerned to evaluate the macro-to-micro linkage where much of the focus is on the specific model required to evaluate the credit risk of the institution. The author mentioned that along with other methods, a great number of financial institutions use stress testing risk management techniques to determine the minimum amount of capita which is necessary for limiting their portfolio exposure. Stress testing can be used to forecast shocks on the market conditions which may successfully be used to manage the credit risk of the financial institutions.

This section looks at the step that are needed to carry out in order to create a stress testing scenario using macroeconomic model where the model may include endogenous variables. Bearing in mind the fact that such models do not consider variables from the financial sector therefore satellite model is generally used to map micro variables such as asset prices and other along with macroeconomic variables to determine the impact of asset prices on the credit loss experienced by financial institutions. The same process can be shows in the following diagram; 


\section{Figure 1. Credit R.isk-A Typical Macro Stress-Testing Process}

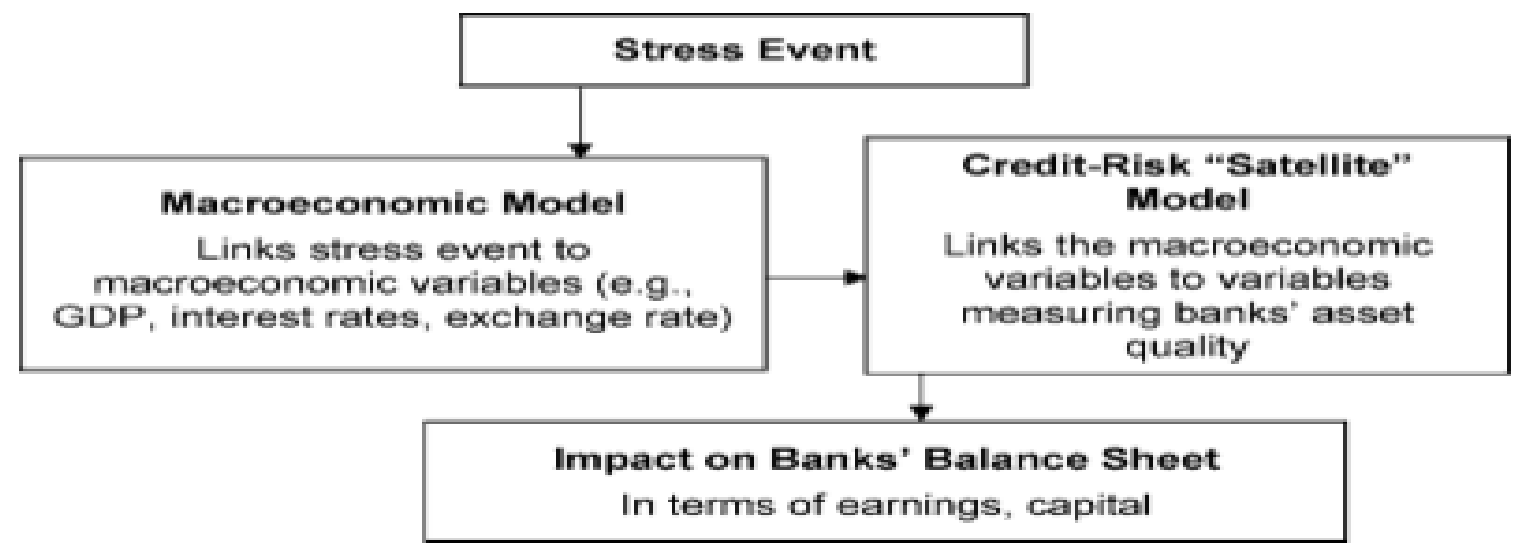

Source: Bank of Japan (2007)

As shown in the figure above, the framework is used to carry out stress testing in financial institutions to gauge credit losses that may be experienced in case of changes in the macroeconomic variables. This will allow the management to cover losses with the buffer of capital put aside after the evaluation of credit risk. The above stated approach has number of benefits; however, there are some challenges as well. It has been observed that the approach is weak in terms of evaluating the interaction between key financial systems; in addition, the feedback impact is also absent in this model. Other than this, there are some approaches towards stress testing that do not consider the distribution of the credit losses that is experienced by the financial institutions as well as aspects such as structural breaks.

\section{Stress testing mechanism in European Countries}

During the times of past waves of economic recessions and global financial meltdowns, many of the European countries have also suffered on some realistic note to such waves of economic downturn, especially the industries related to financial institutions and banking 
networks. However, the waves of such global economic meltdown were so strong and consistent that the higher authorities started to pay some serious attention and head on the issues related to stress testing approach and mechanisms. The concerns shown by them was quite justified and logical, because the phase of such global economic downturn was so pervasive, that the future economic predictability and business outlook was declining and becoming blurred on day to day basis. Thus, the higher regulatory authorities of EU including European Banking Authority (EBA), specifically plans to carry out certain stress testing mechanisms, over the credit risks and management related areas of some major and significant financial institutions and banking companies that falls within the region of EU specifically.

Out of many, one of the significant and most key responsibilities of EBA is to ensure the consistent and orderly integrity and functioning of financial institutions and banks operating in the financial markets in the region of EU and with that it also cross checks the ultimate stability of the overall financial system in EU as well (Eba.europa.eu, 2014). To this end, the EBA is mandated and obliged to clearly monitor and manage the overall assessment and evaluation of key market developments, as well as to identify potential trends, probable risks and vulnerabilities rooting out or stemming up from the macro-prudential level and micro-prudential level.

However, one of the most key and basic supervisory tools with which, the conduct of such economic and financial analysis is taken out by EBA was the EU-wide stress testing exercise. Hence, the EBA Regulation thoroughly gives its relevant Authority, with regard to relevant stress testing responsibility, power and command to initiate and appropriately coordinate the EU-wide stress testing techniques, in collaboration and contact with the European Systemic Risk Board (ESRB). 
Specifically, the primary goal of such tests was too deeply evaluate and assess the resilience and tolerant level of such financial institutions and banks, practicing all around the region of EU, to most of the adverse market situational developments and progress, and as well as to provide its feedback and results after the performance of stress tests, in order to contribute to the ultimate analysis of systemic and operational risk on the overall financial framework and system of EU. Consequently, EBA's EU-wide stress tests were immensely conducted and performed in a bottom-up fashion, using some valid and consistent stress testing tools and techniques, scenarios and core assumptions were specifically made and developed, in cooperation with the ESRB, the European Central Bank (ECB) and the European Commission (EC) (Eba.europa.eu, 2014).

Furthermore, hundreds and thousands of ECB external, internal and other typical subject related auditors have also keenly and objectively begun to examine the records and information pertaining to the various balance sheets of many or most of euro-zone banks (Seith, 2014). Moreover, they are also planning and diverting their additional interests on the areas like stress testing on the relational aspects of the bank operating in the Euro zone. With European Central Bank performing the role of supervisor and will acts as an oversight for whole of this operation and methodology and therefore, it is also predicted on certain valuable grounds, that soon the ultimate financial and economic position of EU's financial industry, encompassing the banks and financial institutions, in particular, would return to strong commercial and financial health prospective.

But on the other hand, there are certain risks and financial dangers as well. Risks or dangers in a sense that, after the audit of the structure of various vital and essential facts and figures incorporated into the balance sheets and related records of these banks, a true and 
realistic picture of most of the Euro zone banks will be significantly highlighted. These highlights then would be clearly denoting and demonstrating that whether such banks are primarily under the scale or level of minimal credit risks that must be associated to banks at most. And if not, means if these banks breached those minimal level of credit risks management methodology, then there would be a strong chances that some strict financial regulation being implemented on the overall financial and economic structure of banking and financial institutions, in all over the Euro zone banking networks and channels.

Thus, the after effect of such assessment by auditors could be deciding one and could take the overall financial industry to some new flourishing levels or it could also happen into vice versa scenario as well. As quoted for one of the banks operating in Euro Zone, years of crisis in Europe's banking industry have taught Martin Blessing a thing or two about dealing with adversity. The Commerz bank head had recently joked with confidantes about how often he and his bank had been left for dead. And yet, both are still around (Seith, 2014).

\section{Identification of major risks with the help of stress testing and the steps of applying stress testing approach}

Stress testing mechanisms proves to be a savior for most of the banks and financial institutions during the times of their liquidity crunch and recessionary phases in an overall worldwide economy or even the cases of their respective economies crunch downs. Since then, many nations all around the globe initiate to apply the phenomena pertaining to this approach towards their financial institutions and related organizations. However, one of the most essential aspects that proves to be of immense help to all of these institutions, was the identification of 
major and key risks associated to credit matters, liquidity issues and other various matters on the overall financial and economic environment of an organization.

But before an analysis and identification of range of risks or vulnerabilities with the help of stress testing mechanism, certain key steps must be followed in an organized way and manner. Because only then, there would be a sufficient and valid chances for the test to be successful in its all regards and area and subject matters and accordingly, an organized level of technique could then be followed and applied. To begin with, macro prudential techniques associated with stress testing could be seen as a multiple steps procedure for examining the core issues and vulnerabilities in the whole system of finance for a particular institution, organization, company or a nation as a whole (Eihak, 2005). The procedure briefly and primarily involves the identification of some major risks, hazards and exposures in the overall financial system, formulation of a questionnaire based approach regarding those identified exposures and risks, appropriately defining the complete and relevant coverage and specification of the required and the necessary data, then calibrating and adjusting the shocks or other forms of related scenarios implemented to the data under review, after then, selecting and applying the suitable testing methodology, and finally, evaluating, interpreting and concluding the results found and calculated (Allen and Gale, 2001).

It would be quite relevant; that stress tests should probe the comprehensive outcome of potential shocks and exposures that are connected to the possible risks that could be faced by an economy or an institution. However, the ultimate process of developing the macro prudential stress testing approach thus, typically initiates with the discussion and explanation of certain probable macroeconomic and financial level risks. Accordingly, the process of discussion and explanation basically recommends some basic and critical kinds of shocks with which an 
economy could be affected during the times of economic hardships and so on, for instance, a considerable and significant rise in the rate of interests, would more likely to impact the economy as a whole as compared to any other forms of economic shocks. Moreover, the reality pertaining to the matter that there are possible availability of certain macroeconomic risks and hazards, that could positively create the shocking environment into the financial system in particular, it does not necessarily mean as if such after effects of shocks would be much greater in substance on the face of the system. This is a mere fact, because the impact of shocks would not be considered as much big, heavy or comprehensive, if the exposures that surrounds to the system is considered as a trivial one or small in nature or essence .

As of now, it is quite clear and visible that the overall objective and goal of the stress tests, is to primarily assess how a particular range of economic or financial risks could be combined with the potential exposures and weakness of the system and most importantly, what could be possible and prospective future affects or consequences of such a risk-exposure combination as a whole. Furthermore, a design of a particular stress test is firmly considered as an iterative and repetitive procedure, as some originally and initially identified and calculated risks could positively lead to certain and relatively lower level impacts on economy or system. But on the other hand, some of the risks which are considered at an initial level of assessment, might be considered as small in nature, but they could also lead to some large and heavy after affects and impacts, if and only if, there would be a presence of a substantial scale of exposures.

There are possibly two ways of raising questions about possible range of exposures presented in a typical national or institutional financial system. Firstly, one can ask a question related to the given scale of plausibility of exposure with the system itself, that means what kind of scenarios can have the worst impact on the overall financial system of a financial institution 
which under the influence of stress testing approach and can be known as the "the worst-case approach". Secondly, one can ask regarding the given or perceived impact or after affect that can be borne by the system, specifically, a question that may be raised includes, what is the most plausible relation or combination of shocks and after affects, that must or would be needed or required in order to have that impact on the system, known as "threshold approach". However, two approaches which are being identified could be considered and used, in order to present or demonstrate the same of level of vulnerabilities, risks and dangers on the face of systems, in two separate and distinct ways.

However, each of the methods being identified in the previous paragraphs, have their own respective benefits and merits, which could be felt and understood, once you analyzed a particular stress testing situation associated to a financial institution, using the both of the above methods. Although, threshold approach is considered as more relevant, consistent and clear, because it mainly deals with a respective threshold, below or above which a situation could be under or over the control level respectively and vice versa. Particularly, with the help of a threshold approach, a certain range of threshold is developed on valid assumptions and facts available. This is done by identifying a range of factors pertaining to shocks and impacts that would be required at a minimal level or scale in order to affect the ultimate financial system of an organization, and if the scale of impacts rest beneath that specified level, then there would be very less chances that the system would be affected due to the outburst of any sort of shocks over it.

In essence, once a set of calibration and adjustment scenarios have been developed and produced with a help of organized technique of stress tests, in a consistent and suitable macro framework environment, then the next step would be to translate and transfer the various 
identified outputs or outcomes of tests, into the face of the financial statement's elements, including balance sheets and state of comprehensive income of a respective financial institutions. Most importantly, there are two broad methods or approaches under which a translation of various macro scenarios can be done into the face of balance sheets and they are: "bottom-up" approach and "top-down" approach (Stid \& Stid, 2014). Specifically, Bottom-up approach is the one, where the impact or after effect of shocks into the system is basically identified and estimated with the help of using the data on the basis of individual portfolios Furthermore, the top-down approach is the one where the measurement of impact done or estimated by using the data on an aggregated basis, that is not on individual basis.

Each of the methods does have their respective merits and demerits, but giving regards to the situation under which they specifically used, consumed or applied. Likewise, the bottom-up approach should normally lead to more accurate, consistent and precise results, but it does possess the disadvantages associated with the areas of the insufficient data or information availability that directly hampers the results of the test and in addition, this approach also surrounds with certain level of complexities in the calculation methods and techniques. On the other hand, shortcomings related to the top-down approach, substantially includes its after effects on applying the overall tests to a comprehensive scale of aggregated data, which could deeply disguise and distract the concentration of exposures and results at the scale of individual banks, institutions and organization. Consequently, such an affects surrounded by a sufficient level of disguise of information, could directly lead to the failures of approach at the individual institutional level and then it would become the source contagion to the remaining and rest of the financial system (Goodhart, Tsomocos and Sunirand, 2004). 
As a result, most of the macro prudential and financial level stress tests mechanisms therefore, endeavors and tries to minimize and overcome demerits of both the systems, by way of combining the overall advantages of two systems or approaches and accordingly, minimizing the disadvantages and demerits of the top-down and bottom-up approaches. Thus, stress tests should be evaluated and interpreted as a means of rough indicators and drivers of exposures associated to economic and financial offsets, rather than applying the approach as forecasts of various financial institutions' and banks' failures and economic downfall. By their nature, stress tests focus on extreme events, not on the most probable events. Moreover, stress testing estimations and calculations, no matter how complex or technical they are or which relevant or state of the art the model are being applied or used, there would be the possible chances of ignorance or deficiencies, in the ultimate demonstration of results associated with the systems of financial institutions or related enterprise. Essentially, the approach is most often used to their fullest and relevant extent, in order to get persistent and rather appropriate approximations of definite or true or real or potential loss and risks exposures in the system.

Hence, each of the methods that surpasses to the definition of stress tests do have their own firmness and shortcoming, but history has strongly proven that such techniques are much relevant and successful in demonstrating the realistic version of a financial and economic systems of institutions and organization on the future prediction scales. Consequently, the range of stress tests is being termed as a successful venture of methods, which primarily identifies various future risks and exposures in favors of the entity on proactive basis. Some of these risks include liquidity risks, efficiency risks, financial risks, cash flows risks, economic sustainability risks, future economic risks at a national level and many more. Each of the risks being revealed 
or yield specifically, dependent on the mode of test you are brought followed with and types of the stress test in particular. However, each of such methods and approaches of stress testing's do have their relevant favors, shortcomings, weaknesses, merits, benefits and other form of characteristics analysis.

The following graphical representations and pictorial analysis comprehensively displays and demonstrates some key and additional mode of analysis and assessments of various European and United States banking channels soon after and before the impact of stress testing mechanisms on the concerned banks and financial institutions.

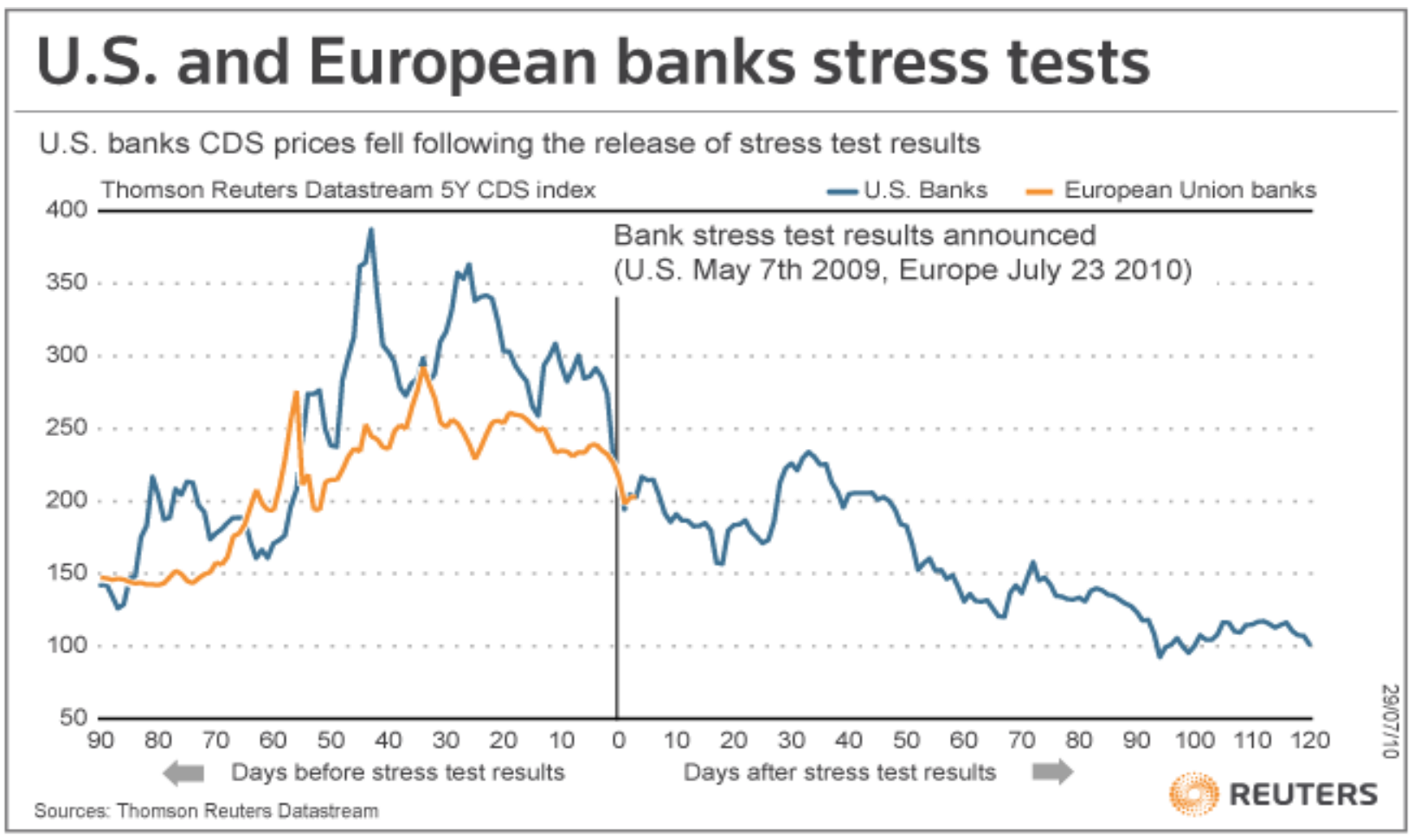

Reuters graphiseott Barber

Source: (PROFITEERING, 2010)

There are internal (micro-prudential) merits and benefits in becoming practical and sophisticated and in addition, being more realistic in applying stress testing methodology, and in particular, diversified and significant external (macro-prudential) advantages to the whole system 
of banking sector, as the last year's and current year's stress tests results have specifically shown in the above graphical representations in lowering of a huge range of credit default spreads over the gradual levels. As, it is quite clear the from the graphical analysis and presentation of certain US and European banks, as illustrated in the above picture, that the impact on the prices of CDS concluded as a dramatic fall soon after the results of stress testing was made public. Thus, the results clearly shows that the impact of certain applied and distinct methodologies of stress tests over the banking channels in these two vast regions, was merely concluded as negative and adverse over the prices of the respective commodities offered by the range of these banks. 


\section{Who's stressed}

Additional capital some major banks need (can be raised by selling assets, raising money from investors, converting shares or using bailout funds):

\begin{tabular}{|c|c|c|c|}
\hline $\begin{array}{l}\text { Financial } \\
\text { institution } \\
\text { JPM Chase }\end{array}$ & $\begin{array}{r}\text { t cap, } \\
\text { illions } \\
\$ 139\end{array}$ & $\begin{array}{c}\text { TARP funds, } \\
\text { in billions } \\
\$ 25.0\end{array}$ & $\begin{array}{l}\text { Money needed, } \\
\text { in billions } \\
0\end{array}$ \\
\hline Wells Fargo & 114 & 25.0 & 13.7 \\
\hline Bank of America & 81 & 45.0 & 33.9 \\
\hline Goldman Sachs & 64 & 10.0 & $\mathbf{0}$ \\
\hline US Bancorp & 37 & 6.6 & $\mathbf{0}$ \\
\hline Bank of N.Y. Mellon & 35 & 3.0 & $\mathbf{0}$ \\
\hline American Express & 32 & 3.4 & $\mathbf{0}$ \\
\hline Morgan Stanley & 31 & 10.0 & 1.8 \\
\hline MetLife & 26 & 0 & $\mathbf{0}$ \\
\hline Citigroup & 21 & 45.0 & 5.5 \\
\hline PNC Financial & 20 & 7.6 & 0.6 \\
\hline State Street & 17 & 2.0 & $\mathbf{0}$ \\
\hline BB\&T & 15 & 3.1 & $\mathbf{0}$ \\
\hline Capital One & 9 & 3.6 & $\mathbf{0}$ \\
\hline SunTrust & 7 & 4.9 & 2.2 \\
\hline Regions Financial & 5 & 3.5 & 2.5 \\
\hline KeyCorp & 4 & 2.5 & 1.8 \\
\hline Fifth Third Bancorp & 3 & 3.4 & 1.1 \\
\hline GMAC & N/A & 5.0 & 11.5 \\
\hline
\end{tabular}

Source: (PROFITEERING, 2010)

Furthermore, the above table is primarily based on some major financial institutions that are established throughout the region of US and all of them have a significant market share in terms of their respective specialty in terms of their business areas and concerns. The data basically, suggests some of the mechanism and tools, in order to raise major capital requirements 
of banks and financial institutions in these regions, during the times when the results of stress tests are quite negative on their overall financial and economic future and current business frameworks. Consequently, some of the tools to raise the major capital requirements of these banks and financial institutions can be fulfilled through bailout funds mechanisms, selling out or disposing major assets of banks, raising finance from some strong and stable investors or group of investors and converting equity shares in order to get proper liquidity channels for them.

\section{CHAPTER 3: RESEARCH METHODOLOGY}

Research methodology or mechanism is primarily concerned with the accumulation and selection of data, statistics, and information's, materials and other facts and figures specific and related to the research. The overall strategy selected and chosen with regard to the ultimate research methodology has a key role to play in the whole context of your research. Furthermore, the overall outcome or consequence of any research is basically dependent, on the structural framework related to the research technique and tools, on the basis of which the whole research is based. However, the pre-selection of a valid number and range of research methodology and mechanism is quite a smart aspect by a researcher, researching any means of topics from this world as a whole.

Research methodology of a dissertation or thesis writing is considered as one of the most critical and crucial stage or chapter of the paper, because the ultimate accuracy of the results and findings are mainly based on the reliability, accuracy and validity of the methodology adopted by the research paper (Cohen et al, 2003). Therefore, this indicates that it is important to carefully organize and carry out and planned out the research methodology section, which would then assist the research in getting the justification for the research aim and objectives. 
Hence, the primary and secondary modes of research could be valid for any topic in most of the instance, but the selection of each of such methodology has its valid and comprehensive impact on the overall product of the research paper. Therefore, the part related to the development of a perfect or ideal research methodology, even during the stage of proposal for research and soon after the dissertation working actually initiates, is a key process and procedure (Bell, 2010). Moreover, such a process is of iterative in nature and would require in most of the cases to review, update and incorporate any sort of changes or developments in the overall working mechanism of the research paper in it. Consequently, you will have the better chances to achieve far better results as compare to your colleagues, if wisely and consistently followed the above-mentioned steps and suggestions pertaining to the research methodology and its development.

\section{1: Research Paradigm}

Easterby-Smith et al,(2008) discussed that broadly speaking there are two categories of research paradigms where the first one is postivist approach while the second one is sociointerprevitism approach. The authors mentioned above defined the postivist aproach as paradigm that is based on the quantitiave research apprach, which simply means that the researcher of the study is able to justifiy the topic under study from objective point of view. The steps undertaken in the research paper includes testing of the stated hypotheses, applying the various other statisitcal methods of testing and analysis of data, applying mathematical appliations and models in testing and assessment of the overall data, informatoion and their analysis. In contrast to this, the socio-interpretivism approach, as defined by the authors is qualitative research approach 
where the researcher justifies the research objective, goals and aims of the study from personal, practical and reslistic viewpoints and beliefs.

However, in the later approach, the results and findings of the paper are influenced by the researchers' beliefs and viewpoints. Looking at the nature of this particular dissertation, it can be said that the positivist approach is better compare to the socio-interpretivist approach as it allows the researcher to extract data and then test the stated hypotheses using different research techniques. Furthermore, when linking the socioi-nterpretivist approach to the topic of strress testing to wards the assessment of credit risk for financial institutions and banks, it would be quite difficult and technical to interact such an approach to this stress testing approach in feasible terms and relistic environemnt. Because, stress testing is an approach that is basically applied and implemented on the financial and economic systems, of any nation, organization or financial institutions, in particular, and it do have its own reslistic assumptions and acadmics, which could not specifically connected with the writers or reseracher own sets of belief or viewpoints on most of the extent.

However, research may provide his or her view related to the topic, while applying the approach of socioi-nterpretivist, but he or she cannot completely connect the topic of research with such an approach. And it is so, because stress testing approach do have its own estalished sets of mechanisms, priciples and trastitions, which could not be ignored or adjusted to a greater extent and thus, the writer would have to limit his research to certain quantiative aspects so as to successfully demonstrate certain valid and usefull centre points of attractions of his or her research readers in particular. 
On the other hand, the research paradigm pertaining to postivist, mainly allows the research to validly put forward his or her objective view on the topic opf research based on certain quantiative terms, analysis, calculations and analysis. Furthermore, this approach also favors the researcher to successfully apply certain practical environment scenarios to the topic of research. As in our case, I have positively applied certain graphical presentation, pictorial affects and graphical representation of the avaliable data related to the topic of stress testing in particular.

Moreover, various sorts of literature review, discussed in the section, especially pertaining to the European and Chinese financial institutions and banks, spsecifically illustrated with certain quantitative terms and techniques of research paradigm. This is the case, because stress testing approach primarily deals with certain set of macro prudential drivers and factors, that significantly helps a particular business organization in assessing its future organization credit risks and exposures, given regard to the present and future visionary circumstances of the case.

In addition, and to be more specific, literature review in this paper, pertaining to solvency stress testing approach, sensitivity stress testing approach and scenario based testing mostly, include the proper and suitable quantitative analysis of the topic under review and research. Consequently, this proves that the postivist approach of research paradigm is quite integrated with the topic of stress testing that I have under taken and moreover, the approach that has been selected proves specifically fruitfull for me, in analyzing my research topic in more depth and critical way. 


\section{2: Research Approach}

There are two research approaches where the first is qualitative while the second is quantitative research which is explained by the authors as follows; qualitative research approach is a type of dissertation where the researcher tries to gain deep understanding of the factors related to the environment, thus it is has a more subjective nature. On the other hand, the author explained quantitative research as more objective in nature where the researcher is focused at developing and testing the hypotheses and evaluating the cause and effect association between variables and drivers. Thus, each approach has its own basic notional aspect in carrying out the way of research. Likewise, qualitative approach, mainly surrounds to the analysis of some subjective aspects of the research, that includes the assessment of wide range of discrete and connected attributes, traits and characteristic of the research topic itself, and thus, on the basis of those selected and assessed attributes related to topic under research, the overall outcome, conclusion and recommendations on the topic is based.

On the other hand, quantitative approach is quite numeric and practical in nature. Most of the organizational set ups are already indulged in such a numeric approach in their daily routine life. And similar is the case with stress testing mechanisms, which is keenly and positively carried out by most of the recent and past financial organization establishments. An all such analysis and evaluation is purely based and linked certain numeric and quantitative techniques and approach. And most specifically, the analysis of research topic of this paper, i.e. stress testing approach, mainly deals with the macro economic factors and drivers, pertaining to the interest rates, taxation policies, cash flow requirements, liquidity needs and so on, therefore, 
quantitative approach would be more reliable and suitable for stress testing approach (Lee and Pan, 2010).

Most importantly, the nature of this dissertation also indicates in great terms, that it is based on extracting data from different sources, developing hypotheses, applying graphical representations, pictorial effects, charts, tables and other mathematical and statistical analysis, tolls and methods and evaluating the relationship between various variables, factors and economic drivers and, therefore the research approach for stress testing approach is primarily based on the methods and means of quantitative research approach.

\section{3: Research Strategy}

Connaway and Powell (2010) mentioned that research strategy assist the researcher in setting up the steps that will provide the details about how the research works will be carried out, in order to get reasonable justifications for the research objectives, aims, significance and questions and answers. Moreover, the research strategy is no doubt one of the most important and key aspect that directly deals with the ultimate procedural flow, of gathering of research information, knowledge, data and related materials. Hence, the flow of each and every bit of information that is to be gathered, organized, analyzed, assessed, evaluated and summarized and finally conclusions are placed over it, must be appropriately selected from relevant secondary and primary sources of research bank, whether, is from the internet sources, libraries, encyclopedia or any other mode of research resource gathering methodology. However, the point that is to be embarked over here is that, the research strategy must be planned on a proactive basis before the time you actually start to work over the dissertation and should be revised and 
reconsidered as and when require, giving regard to the special needs and circumstances under which the research have been performed.

In essence, and broadly speaking, there are four different strategies that can be used to extract data for this dissertation and research paper; for instance, grounded theory, case studies analysis, structured and unstructured survey and respondents' interview. All of these methods and research strategies do have their own merits and demerits, related to the topics that have to be covered under the research. But, all these research strategies and methods are quite distinct from each other in theory as well as in practical terms as well. As grounded theory research strategies primarily deals with the pre-written theories and readings based on the research topic in particular, however, it is not the same as the literature review in substance.

Secondly, case studies analysis, relates to the assessment of the particular or respective case which can be positively and substantially integrated with the topic of the research in successful manner, and thus, the overall results and conclusion of dissertation could be based over those case studies. Anyhow, case studies analysis could seems quite difficult in one or the other case of the research, but, it does proves to be bit helpful for those topics which are basically based on some numerical and calculative aspects of the data of the research in particular.

Furthermore, structured and unstructured survey mode of research strategy, primarily deals and includes various forms of surveys that is mainly conducted by the researcher over the subject of his or her research. Structured surveys represents pre-organized sets of research questions or related information that has been included in the subject of the research surveys, however, unstructured mode of survey surrounds to a bit haphazard way of strategy, in which most of the data or information is kept open by the researcher, which is then appropriately filled out by the general public or other people, on whom the research survey is primarily based on. 
Lastly, interviews techniques are also being considered much attractive and efficient for various subjects of the research at times, because interviews sessions mainly held among a few set of peoples or targeted audience with respect to the subject of the research helps a lot in many ways. Such sessions may provide and gives out certain practical experiences and reality checks on various aspects and facets of the research subjects and it can also positively provides the researcher with various sets of certain views and feedbacks from the general people about the research topic. However, such interviews session could also be merged with the tools of questionnaires-based interview as well.

However, particular to the topic of this dissertation, which is primarily based on the stress testing approach for credit risk analysis for financial institutions, a mixed gel of these research strategies have been duly followed and applied over the subject of the paper. Since the research topic is based on carrying out stress testing to evaluate the credit risk of the banks and financial institutions, therefore, data related and connected to the practical and technical variables, diversified macroeconomic drivers and indicators, different methodologies of stress testing used and effects and consume ability of the approach in the region of Chinese and European financial institutions and markets, has been thoroughly extracted from diversified range of financial reports and financial statements of the institutions in particular and where required (LeeGosselin, 2005). Moreover, only such data has been extracted out from the respective technical and financial reports or financial statements, of the respective regions and institutions, which are specifically relevant and suitable for the discussion that has been undertaken. Likewise, the discussion of such factors and the data analysis specifically demonstrates that the use of research strategy for stress testing approach is mainly based on the sources of secondary data rather than the primary data. 


\section{4: Data Collection Method}

The research topic of this study is to use stress testing approach in terms of evaluating the credit risk of the financial institutions. For that matter, information and data related to the financial and economic information will be extracted from the financial statements, technical feasibility reports, research and graphical model and curves, pertaining to the stress testing mechanism and its usage and practicability, of various banks and financial institutions. Furthermore, the study will be a pooled data research paper where the financial information will be extracted from both Chinese and European financial institutions and from 2000 till 2013, in order to evaluate the impact of the Global Financial Crisis and other economic downturn situations, on the credit risk of the bank which in turn would influence the overall performance and profitability of the financial institutions. Stress testing will be carried out using the financial information to evaluate the credit risk of the financial institutions and thus, recommendations will be provided based on the results and findings.

In addition, the main data collection mode was the secondary mode of research data gathering and collection. Moreover, the resources available on internet in the form of various financial analyses, reports, discussions and commentaries, on the respective financial institutions and banks in line with their stress testing approach, have been appropriately and valid incorporated in the analysis and assessment of the topic of the research (Smith, 2008). Moreover, various technical reports over the study and practicability of different methodologies of stress testing based on the economic and financial system of institutions have also been thoroughly studied and used in the dissertation. Further, some of the statistical data and recent developments in the fields of stress testing, especially related to the European and Chinese regions have also 
been incorporated in the research paper, where it seems justified and logical to link those materials to the basic subject of dissertations.

However, some of those discussion and practical scenarios explanation might have been performed in deeper way, but, however, they would seem interesting and attractive for the range of readers who would specifically linked the concerned scenario with the real-world financial problems and economic crunch downs. Even though, the information and data that have been extracted and applied in the subject of this dissertation, has been thoroughly checked for their originality and then accordingly, they are reproduced and reorganized to meet the respective requirement of the discussion under progress. Thus, on broader terms, the data collection methods followed for the dissertation is mainly surpassed on some secondary data collection research methodologies, to great extent.

\section{5: Data Analysis}

The technique that will be used in this research paper is stress testing which is defined as a simulation technique using the asset and liability portfolios in order to examine the impact of different economic events on the financial health and position of the financial institutions. Stress testing can also be used to measure the impact of certain stressors on a particular industry or sector (Rosche and Scheule, 2007). Rebonato (2010) mentioned that stress testing is a risk management technique which determines that how the value of the portfolio will change in response to a financial crisis. One type of stress testing technique is Monte Carlo Simulation. In this report, we have based our discussion and analysis on the use of sensitivity analysis, scenariobased stress testing, solvency stress test approach and macro prudential stress testing mechanism, 
which are multiple factor model that has helped in carrying out the overall research on the topic of stress test.

Furthermore, in the section of literature review and throughout the structure of this dissertation, each of the relevant commentary, journal article, website reference, newspaper sources and other forms of citation references, have been deeply analyzed and assessed, by keeping in view the core subject requirement and basic objective behind the entire dissertation. Firstly, each source have been properly presented and incorporated in the paper with help of the statement, conclusion or facts represented by each of the sources. After that, each of such disclosed sets of materials and data in the paper have been thoroughly analyzed and evaluated based on my point of view, research strategy, observations, knowledge and other practical and technical aspects of the stress testing subject in particular.

As a result, the outline and overall structure of the paper is much organized, clear, comprehensive and a learning one for the new or even experienced readers of the paper, regardless of their previous knowledge and linkage with the topic of stress testing in the practical world scenarios (Sandelowski, 2000). Moreover, the data, reports, graphs and other pictorial and historical effects used in the paper, under the section of literature review, stressfully mentioned and demonstrated a varied set of results and consequences pertaining to the subject of paper. Particularly, how the different types of stress testing mechanisms, including, solvency testing approach, scenario-based approach, macro prudential approach and sensitivity approach, have their respective merits and shortcomings. But, as per the discussion and arguments made under the paper, the most accurate and better approach is known as macro prudential approach. This is so because this approach has one of the strong and optimistic front ends, in the form of clear and vivid description of certain important macro-economic factors and drivers, with the help of their 
identification, a financial company and banks can have much better and consistent results over their financial systems.

Furthermore, one more consequential conclusion pertaining to the approach surrounds to the fact, that each approach of stress testing must be selected in accordance with the economic and financial environment of an economy under which a company is performing its operations, then related risks, hazards and exposures must be identified giving due regard to the external financial environment and then finally, concluding the results of the tests. This entire testing and analysis is comprehensively mentioned and detailed out in the last section of literature review of this paper.

\section{5: Limitations of the Research Paper}

As mentioned in the previous headings that based on the nature of this research paper, the most suitable research strategy and research approach chosen for this report is quantitative research approach which is based on the analysis of objective data. Therefore, the major limitation in this research paper is the lack of availability and accessibility to the data; in addition, the accuracy of the data is also a major factor that may influence the results of the study. In order to carry out stress testing, the researcher needs to have sound knowledge about the type of stress testing which will be used in this research paper so as to arrive at better results.

Furthermore, for the literature review section of the research paper, the secondary data is extracted from the financial statements, financial reports of financial institutions and banks, technical analysis report on stress testing mechanism in particular, and given due regard to the practical financial environment of European and Chinese financial markets, structure printed, 
graphical and pictorial effects of various forms of data and finally, certain online web sources, which in substance carry their own disadvantages and limitations. These include, such as cost and time constraints as well as many of those may also require a lot of efforts on the part of the researcher, like the researcher would have to read it specifically in context with the subject of stress testing in his or her mind throughout the entire reading and analysis sessions. And if any of diversion or lack of interest is created during the reading or analysis sessions, pertaining to any secondary resource, being analyzed, then the overall purpose, meaning and conclusion of the subject could be devastative effaced and the purpose of the research could be compromised (Pasmore and Woodman, 2007).

Anyhow, much of those limitations have been accordingly offset by me, as I have thoroughly and stressfully concentrated towards each of the topic that I have gone through and evaluated over the internet or other sources, and in addition, also read some of that more than one time. But anyhow, still there are chances that some of those topics, have been over stretched or under estimated by the respective fame of minds that I was carrying during the time of actual research. Finally, some other limitations experienced by the researcher may also influence the quality of the work such as lack of knowledge, technological errors and other limitations related to the inability to analyze the outcome of the results appropriately and accurately.

\section{6: Ethical Considerations}

In order to enhance the overall reliability and validity of the research outcome it is necessary that the researcher should keep in view the ethical implications while carrying out the research study. The data should be extracted from reliable sources, for instance, it is better to extract the financial information from the annual statements of the financial institutions rather 
than from any other web sources (Goddard and Melville, 2004). It is a very important factor and aspect for the researcher in particular and the reader of this dissertation in a general sense.

Because, most of the reader may substantially base their future or current way of thinking, with respect to the subject of dissertation, merely on the researcher sole paper that would have been placed over the internet in some period of time from now and consequently, if the sources were not reliable or the research fails to duly comply with the proper measures of ethical consideration during the phase of his or her research timeframe, then the after effects of such research results may impact such readers adversely and in a pervasive manner.

Hence, the researcher must understand his due responsibility towards the carriage of particular care and ethical aspects and considerations, when using or utilizing any of the materials from the sources like internet or etc., onto the face of his or her research paper, because, lack of any form of ethical consideration may hamper the overall quality of the paper and also the well-being of certain devoted readers of the research paper, in particular. Finally and most important aspect to mention here is that, the results or outcomes of the research paper should not be forged out, miscalculated, biased one, subjective, suiting to one's personal or professional jealousies, misrepresented and must be in such manner, that negatively affects the interest of its reader in a generic terms and manner.

\section{CHAPTER 4: RESULTS AND FINDINGS}

Stress testing mechanisms and the usage of its techniques, in order to analyze and evaluate the credit risks and other major risks associated to the organizational setup of banks and financial institutions is undoubtedly considered as one of the complex and technical task. As discussed in this paper, it is quite evident from the analysis and mechanisms explained over 
various diversified practical environment and scenarios, that to approach one specific approach for stress testing would not be feasible or reliable for all or most of the financial institutional setup and banking channels, in particular.

Therefore, a topic needs a due consideration and a through expertise along with a technical and financial competency in order to reach to a sustainable findings, results and analysis outcomes. Anyhow, the subject of my dissertation is quite technical, complex and comprehensive and do possess multiple dimensions in each of its smallest sub topic, but, on the basis of my analysis, assessment and critical evaluation of the topic, in following paragraphs there are some of documentation of my research findings and results.

No matter which methodology of stress testing is applied, to test the future economic or financial dependability of concerned banks or financial institutions, the identification of various key and core macro prudential and micro prudential economic drivers, indicators and determinants is very essential before the further progress over the test can be made. These indicators or drivers would include current liquidity requirements, cash flow (both inflows and outflows) needs of an organization, general economic outlook in future (which can be assessed with the help of management and economic experts), interest rates drivers, inflation rates tools, factors of production needs for an organization and many more to include, depending on the specific requirements and needs of the organization.

Furthermore, solvency stress testing methods is firmly and strongly regarded as one of the most robust and effective phenomena of stress testing, which was identified by IMF support team after the intense efforts and endeavors. Consequently, solvency stress testing approach specifically identifies various key and unique dynamics, of macro prudential factors on the future grounds in favor of the organization and in addition, it also helps in delivering some consistent 
results over the range of period for most of the financial institution with the help of its enormous mode of practical methodology.

Moreover, stress testing approach does not only highlights or depicts specific results pertaining to the credit risks, hazards or exposures that a typical financial institutions bears, but on the other hand it can be comprehensively utilized in order to assess some other vulnerabilities and exposures or risks with which a typical banks or these institutions can be affected. These may include, calculation of future GDP growth rate, future rate of imports a nation have, analysis of balance of payment on expectation levels, rate of unemployment, inflation, interest rates, taxation impact and the affects of business cycles on the future growth of organization and many more.

In addition, and one of the most important findings includes, that stress testing mechanisms is not a tool or technique, which is specifically applied during the times of economic downfall or meltdown or recessionary phase, but, its circumference falls under the normal working methodology and functionality of all the financial institutions and banks. Similarly, they need to perform its applications and methodology over their entire financial system on regular intervals.

Furthermore, it is quite interesting to quote here, that soon after the emergence of global economic crisis in the period of 2008 and 2009, many financial institutional setups and banks, especially in the regions of China and Europe, regularly conduct stress tests over their entire system of company.

Another important cause of concern that forms a significant eye-catching attitude from this research paper, is that many of the financial institution and banking networks do not encompass much employees who are properly and reasonably aware with the phenomena of 
stress testing approach and its importance in the overall future well-being of an organization. Similarly, this is a great cause of concern for those institutions, as the personnel working in those institutions mainly have to deal with the transactions related to the credits, finance, economics, interests, repayments and etc., therefore, it is expected that they should have at least a basic knowledge and information regarding the term like, stress testing.

Finally, as the research paper specifically points out that most of the institution now regularly conduct and carries out, certain stress testing mechanism or approach over their financial and economic system on a regular basis. But most of them do not follow the most suitable way of its working, which appropriately highlights the wide range of future risks, credit risks, exposures, economic vulnerabilities and many other risks along with their possible impacts, on the face of the organization as well.

This discussion have thoroughly been explained and mentioned in a detailed manner, in the section of literature review, under the heading of "Identification of major risks with the help of stress testing and the steps of applying stress testing approach”. Hence a brief look out and thorough concentration of readers on this section, will make them feel in an appropriate manner, the overall importance of this specific matter and issue related to stress testing approach.

\section{CHAPTER 5: CONCLUSION AND RECOMMENDATIONS}

Furthermore, at the end of this paper, there are couple of fruitful recommendations that I want to present and forward to the managers of financial institutions and banks, located in the circuit of entire world, and especially in the circuit of European and Chinese region, and they are detailed out as follows; 
- The methodology of stress testing should be performed and applied on the overall financial system of an entity at least once a year and if organization is operating under the fluctuating economy, then it should be carried out at least twice a year. Such an act on the part of the management would make them absolutely informed, with regard to future growth, standing and well-being of their organizations.

- Each and every indicators and drivers, whether macro based or micro based, that are basically the subject of the stress testing for the organizations, must be checked on a regular basis by the managers and appropriate measures should be taken out by the managers in order to keep those economic drivers and indicators under control, so that the result of stress test might not come against the organization on substantial terms.

- Finally, the managers should entail the regular trainings and developments sessions for the relevant employees of their organization, in order to make them completely knowledgeable and more informed and aware, with respect to the developing science, theories and practicalities of discrete range of mechanisms of stress testing, which can be suitably applied to the overall financial framework and system of multiple financial institutions and banks.

In a nutshell, it is quite clear from the analysis, which have been demonstrated and displayed in this dissertation, that such an approach is much essential, useful and even resourceful, for most of the financial institutions and banks, dispersed all over the globe. Because it is considered as one of the foremost tool and method, in determining the overall credit risks, financial exposures and other forms of future vulnerabilities in favor of a particular or typical institutions and banks. Moreover, the stress testing is basically the methodology with the help of 
which certain future macro prudential and micro prudential economic drivers and indicators are gathered and analyzed, with the primary intention of assessing the future financial an economic well-being, growth level and status quo of a set of financial institution, banks, organization, credit institution or economy or a nation as a whole.

An introduction also contains some relevant comments and explanations pertaining to the significance of this paper, research questions and overall aims and objectives of the research. However, the key objective of the paper primarily lies around the fact; of evaluation of some discrete and distinct stress testing approaches existed in the practical world of financial system of banks and financial institutions. And how often, these strategies are merely used and applied by various institutions and banks over their financial systems in the phases of global economic depression and under normal economic scenarios.

Moreover, the aims also encompasses the major credit risk evaluation techniques with the help of stress testing approach and the implications of those risks and hazards over the ultimate financial system or capability of the organization in particular. Significance of paper primarily lies with the demonstration and transformation of an explicit knowledge and information material with respect to the science and theory and practicability of stress approach and its usage, and in addition, analysis of the approach giving due importance to the financial institutions and banks, which are specifically located in the regions of Europe and China.

Moreover, after the phase of introduction, the section of literature review was initiated, this broadly encompasses some of the major theories, practical scenarios and implications modes of various distinct and differentiated techniques of stress testing in the present and current economic conditions and situations. In addition, few of these reviews were specifically targeted and incorporated in the paper, which substantially and broadly, discussed and overviewed the 
importance, practicability and implementation and conclusions of different approaches of stress testing on the financial institutions and banks especially located in European and Chinese region. Therefore, the economic and financial scenarios were bit different and unique on such specific targeted systems of globe, when connected with the theoretical and practical aspects of stress testing approach.

However, literature review included in the paper, significantly described some big deal of stress testing methodology all over the globe, its impact, its efficiency, its effectiveness, its positivity, its suitability and various other aspects. Furthermore, comments, analysis and discussion were also included during the times of global economic meltdown that the world faces during the reign of 2008 and 2009, which completely transforms the overall economic structure and framework of the entire world in glimpse of an eye. Thereafter, the paper comprehensively discusses various research methodologies and certain related attributes connected to research, that includes, research paradigm, research approach, research strategy, data collection methods, data analysis techniques, limitation of the research and some due regards were also given to ethical considerations in planning out and developing the content of this dissertation.

Finally, some major and key findings and results were incorporated in the paper under the section of Findings and Results, which stressed out and pointed out some of the valid and fruitful findings and outcomes, on the basis of the analysis performed in the paper. Hence, each aspect and part and section of this paper was specifically given their due weight age and considerations, in constructing the content of this dissertation, which comprehensively includes, introduction, literature review, research methodology, findings and results. 


\section{REFERENCES}

1. Alessandri, P., P. Gai, S. Kapadia, N. Mora, and Puhr, C.(2007) 'A Framework for Quantifying Systemic Stability'. Preliminary paper presented at the workshop 'Stress Testing of Credit Risk Portfolios: The Link between Macro and Micro" hosted by the BCBS and the DNB, Amsterdam.

2. Allen, F. and Gale, D. (2001). Comparing financial systems. MIT Press Books, 1.

3. Andersen, H., T. O. Berge, E. Bernhardsen, K.-G. Lindquist, and Vatne, B. H.(2008) A Suite-of-Models Approach to Stress-Testing Financial Stability.Staff Memo No. 2, Norges Bank.

4. available at http://www.imf.org/external/pubs/ft/wp/2008/wp08206.pdf

5. Bank of Japan. (2007) The Framework for Macro Stress-Testing of Credit Risk: Incorporating Transition in Borrower Classifi- cations. Financial System Report (September).

6. Basel Committee on Banking Supervision (2008) Principles for Sound Liquidity Risk Management and Supervision, September 2008

7. Bayoumi, T. and Vitek, F. (2011). Spillovers from the Euro Area Sovereign Debt Crisis: A Macroeconometric Model Based Analysis. CEPR Discussion Paper No. DP8497.

8. Bell, J. (2010). Doing your research project. 1st ed. Maidenhead: McGraw-Hill Open University Press.

9. Chinadaily.com.cn, (2014). [online] Available at: http://www.chinadaily.com.cn/bizchina/2014-04/04/content_17408243.htm [Accessed 6 Jul. 2014].

10. Committee of European Banking Supervisors (2008) Second Part of CEBS's Technical Advice to the European Commission on Liquidity Risk Management: Analysis of Specific Issues Listed by the Commission and Challenges not Currently Addressed in the EEA 
11. Connaway, L. S., and Powell, R.R. (2010) Basic Research Methods for Librarians. New York: ABC-CLIO

12. Easterby-Smith, M., Thorpe, R., and Jackson, P. (2008) Management Research (3rd ed.). London: Sage Publications

13. Eba.europa.eu, (2014). EU-wide stress testing - European Banking Authority. [online] Available at: http://www.eba.europa.eu/risk-analysis-and-data/eu-wide-stress-testing [Accessed 6 Jul. 2014].

14. Ederington L., Guan W. (2006) 'Measuring Historical Volatility', Journal of Applied Finance $16(1), 5$

15. Eihak, M. (2005). Stress Testing of Banking Systems. Czech Journal of Economics and Finance (Finance a uver), 55(9-10), pp.418--440.

16. Federalreserve.gov, (2014). FRB: Speech--Bernanke, Stress Testing Banks: What Have We Learned?--April 8, 2013. [online] Available at: http://www.federalreserve.gov/newsevents/speech/bernanke20130408a.htm [Accessed 8 Jul. 2014].

17. Fender, I., Gibson, M. and Mosser, P. (2001) 'An International Survey of Stress Tests',Current Issues in Economics and Finance 7(10)

18. Fiedler, R. (2002) Techniques and Strategies for Managing Liquidity Risk, PRMIA Seminar, Warsaw

19. Goddard, W. D., and Melville, S. (2004) Research Methodology: An Introduction (2nd ed.). New York: Juta and Company

20. Goodhart, C., Tsomocos, D. and Sunirand, P. (2004). A model to analyse financial fragility. 1st ed. London: London School of Economics and Political Science, Financial Markets Group.

21. Greenlaw, D., Kashyap, A., Schoenholtz, K. and Shin, H. (2011). Stressed out: macroprudential principles for stress testing.

22. Hall, K. (2006) Stress Testing: Second Round Effects, Reserve Bank of Australia 
23. Howard, S. (2009). Stress testing with incomplete data: a practical guide. Bank for International Settlements.

24. IMF Working Paper No. 08/206 (Washington: International Monetary Fund),

25. IMF/FSB/BIS, 2009, "Guidance to Assess the Systemic Importance of Financial Institutions,

26. Jobst, Lian Ong \& Schmieder, A. (2013). A Framework for Macroprudential Bank Solvency Stress Testing: Application to S-25 and Other G-20 Country FSAPs. IMF Working Paper.

27. Kida, M. (2008) A Macro Stress Testing Model with Feedback Effects, Reserve Bank of New Zealand, DP2008/08

28. Lannoo, K. (2010). The bank stress tests: A work in progress. CEPS Commentaries, 30 July 2010.

29. Lee, J. and Pan, R. (2010). Analyzing step-stress accelerated life testing data using generalized linear models. IIE Transactions, 42(8), pp.589--598.

30. Lee-Gosselin, M. (2005). A data collection strategy for perceived and observed flexibility in the spatio-temporal organization of household activities and associated travel.

31. Markets and Instruments: Initial Considerations," Report to the G-20 Finance Ministers and Central Bank Governors, October, available at http://www.imf.org/external/np/g20/pdf/100109.pdf

32. Martin, A. (2007) 'Liquidity Stress Testing. Scenario Modeling in Globally Operating Bank', Paper presented at the APRA Liquidity Risk Conference, Sydney

33. Moretti, Marina, Stolz, Stéphanie, and Mark Swinburne, 2008, "Stress Testing at the IMF,"

34. Nttdata.com, (2014). NTT DATA launches "Macro Stress Testing Solution" to American Financial Institutions | NTT DATA Global. [online] Available at: http://www.nttdata.com/global/en/news-center/others/2014/040401.html [Accessed 6 Jul. 2014].

35. Ong, L. and Pazarbasioglu, C. (2014). Credibility and Crisis Stress Testing. International Journal of Financial Studies, [online] 2(1), pp.15-81. Available at: http://www.mdpi.com/2227-7072/2/1/15/htm [Accessed 6 Jul. 2014]. 
36. Oung and Bandt (2004) Assessment of Stress Tests conducted on the French Banking System, Financial Stability Review No.5, Banque De France

37. Pasmore, W. and Woodman, R. (2007). Research in organizational change and development. 1st ed. Amsterdam: Elsevier JAI.

38. PROFITEERING?, R. (2010). BANKING ON ECONOMICS: REGULATORS GET TOUGH BUT WILL THEY CAP BANKS' PROFITEERING? [online] Bankingeconomics.blogspot.com. Available at: http://bankingeconomics.blogspot.com/2010/08/regulators-get-tough-in-usafollowing.html [Accessed 12 Jul. 2014].

39. Rebonato, R. (2010) Coherent Stress Testing: A Bayesian Approach to the Analysis of Financial Stress.West Sussex, UK: John Wiley \& Sons, Ltd.

40. report, C. (2014). China to stress tests banks - report. [online] The Sydney Morning Herald. Available at: http://www.smh.com.au/business/banking-and-finance/china-tostress-tests-banks--report-20140404-3639e.html [Accessed 6 Jul. 2014].

41. Rösch, D. and Scheule, H. (2007) Stress-Testing Credit Risk Parameters -An Application to Retail Loan Portfolios. Working Paper

42. Sandelowski, M. (2000). Combining qualitative and quantitative sampling, data collection, and analysis techniques in mixed-method studies. Research in nursing $1 \&$ health, 23(3), pp.246--255.

43. Seith, A. (2014). Bank Oversight: Europe Stressed by Approaching Stress Tests SPIEGEL ONLINE. [online] SPIEGEL ONLINE. Available at: http://www.spiegel.de/international/business/banks-in-europe-concerned-aboutupcoming-ecb-run-stress-tests-a-956668.html [Accessed 6 Jul. 2014].

44. Slack, Hilbers and Jones (2004) Stress Testing Financial Systems: What to do When the Governor Calls, IMF Working Paper, WP/04/127

45. Smith, E. (2008). Using secondary data in educational and social research. 1st ed. Maidenhead: McGraw Hill/Open University Press.

46. Sorge, Marco (2004) 'Stress testing Financial Systems: an overview of current methodologies', BIS Working Papers No. 165 
47. Stid \& Stid, D. (2014). Five Ways to Navigate the Fiscal Crisis (SSIR). [online] Ssireview.org. Available

at:

http://www.ssireview.org/articles/entry/five_ways_to_navigate_the_fiscal_crisis

[Accessed 3 Jul. 2014]. 